\title{
Intervisibility analysis of an offshore wind farm using GIS tools
}

\author{
A. Errico, F. Guastaferro, C. Oliviero \& R. Santamaria \\ Department of Applied Sciences, Faculty of Sciences and Technologies, \\ University of Naples "Parthenope", Naples, Italy
}

\begin{abstract}
One of Kyoto's protocol targets is to limit greenhouse gas emissions produced by human activities through renewable energy and the conversion of wind energy into a useful form of energy (for example electricity) which is a kind of renewable source undergoing strong development.

In this work, the study is focused on offshore aeolic parks. The term "offshore aeolic" indicates wind turbines installed a few miles from the coasts of seas or lakes, exploiting the exposure of strong currents. The offshore aeolic farms have some disadvantages including the impact of these generators on the landscape, but they produce a minimum visual disturbance compared to onshore aeolic farms. Environmental Impact Assessment (known as the EIA), introduced in Europe by the 377/85/EEC Directive and amended three times, in 1997 (Directive 97/11/EC), in 2003 (Directive 2003/35/EC) and in 2009 (Directive $2009 / 31 / E C$ ), ensures that natural resources, usability and identity of landscapes are not compromised by engineering operations. Planning applications must be accompanied by an Environmental Statement (ES), with the purpose of giving an idea about the effect that the operations will have on the local environment. One of the main aims of the ES is the understanding of the likely visual intrusion of the proposed wind farm, which necessitates the use of visual techniques. A visual technique commonly used is the intervisibility map, normally represented by a two-dimensional map, centered on the location of the wind farm. Digital Terrain Models (DTMs) are used to achieve Thematic Maps obtained with GIS software. In this paper, GIS tools are used to identify the effects of wind farms on the landscape; in particular, attention is focused on Map Algebra functions and the study of the analysis of the intervisibility of an offshore aeolic farm is
\end{abstract}


tested in a zone in Italy, localized in the Adriatic sea, along the coast of the Apulia and Molise Regions.

Keywords: offshore aeolic farm, intervisibility, viewshed, GIS, DTM.

\section{Introduction}

In Italy aeolic resources are less exploited than abroad, and one of the causes is the absence of a law about wind energy, unlike solar energy (http://it.wikipedia.org/wiki/Energia_eolica [1]). In recent times the interest in alternatives energy resources to traditional ones, such as offshore wind energy, has been increasing.

In Italy there are not offshore aeolic farms but there are many plans of parks located in islands and in southern areas of Italy such as in the Campania and Apulia Regions where there are the best conditions for wind resources available. In particular, the Adriatic side of Apulia is one of the Mediterranean areas with good potential for exploitation of offshore wind power.

Recently a collection of Guidelines ("Linee Guida per l'inserimento paesaggistico degli interventi di trasformazione territoriale" published by the Environmental Ministry [2]) has been realized. One of these concerns is the correct integration of large works into the environment, especially the insertion of wind power parks in the landscape. The aim of these Guidelines is to give an input to all persons who want to plan or to assess the great engineering works.

The offshore aeolic parks, in fact, have some disadvantages including the impact of these generators on the landscape [3]. The construction of an outsize engineering operation has a significant impact both on the site of insertion, called by Guidelines Local Impact Area (A.I.L.), and on the surrounding area, Potential Impact Area (A.I.P.); the second one represents the geographical space where the impact on the landscape is likely to occur and it is a circular area where the radius $\mathrm{R}$ depends on the number of wind turbines and their height.

At distances greater than the radius calculated, however, the impact is considered negligible.

\section{Intervisibility map}

The minimum distance of visibility is a basic concept to approach the intervisibility. It represents the distance, expressed in nautical miles, at which an obvious beacon is visible from a boat diametrically opposite it on the horizon.

Baldwin et al. [4] defines viewshed as: "two locations in a landscape are said to be in view from each other if they enjoy an uninterrupted view of each other. When one location is specified as the viewing location, and the visibility of all other locations in the study area is analysed, the resulting map of the study area is known as the viewshed or the visible area".

Simulating the insertion of a structure, a map of intervisibility is generally represented by a two-dimensional map whose purpose is to show areas in which the engineering operation will be visible. The aim of these "simulations" shows how the aeolic farm will insert inside the landscape and how it will appear from 
different points, allowing an assessment of environmental impact (Sparkes and Kidner [6]).

Using high-resolution elevation data, standard GIS software can make the intervisibility analysis for landscaping and environmental impact assessment of works characterized by a strong visual impact. The maps, in fact, parameterize the visibility impact of a work on the surrounding areas using different scales or parameters of incidence.

Depending on the type of work analyzed, three kinds of maps will be produced:

1) Map of theoretical visibility, that is independent of distance or size of objects that produce impact;

2) Map of cumulative exposure, that is ideal for maps of wind power farms with large areal extension;

3) Map of the incidence of weighed visibility distance: the visual impact of a wind turbine of $90 \mathrm{~m}$ in height is very different when viewed at a distance of 1 or $10 \mathrm{~km}$, even if the generator is always fully visible.

The map produced for this paper covers both the second and the third case. It is a cumulative map because more aeolic generators are considered and the distance from these turbines is important; it is a weighted maps because the wind park is at some kilometers distance from the coast and so the intervisibility analysis will have more weight for greater radius.

Maps should be themed to make the analysis as well as scientifically accurate, clear and understandable to the layman.

\section{Intervisibility method in ArcGIS 9.x (ESRI)}

To realize an intervisibility map, the software ArcGIS 9.x (ESRI) processes three-dimensional data of a particular area, or rather a Digital Terrain Model (DTM) that shows the height of obstacles in the landscape, with the target represented by a points file.

It calculates if there is visibility between a generic point of observation (observer or spot) and a point to be observed (target). Intervisibility is achieved in the GIS environment by the tool "viewshed": it is a map algebra function that classifies the area around the target into two classes, visible and not visible areas, so that it is possible to develop thematic maps (fig. 1).

The function "viewshed" of ArcGIS 9.2 (ESRI) builds a raster, overlapping on the territory investigated, where for each cell a value corresponds indicating from how many points of view, previously set by the user, the cell is visible. If the observation point is one, the value assigned to the pixel is equal to 1 or 0 depending on whether or not one can see the enclosed area from it.

When the target is not only one but the visibility needs to be evaluated from multiple targets, intervisibility function records the number of targets visible by the observer and the value assigned to the pixel is equal to 0 (not visible) or different to 0 (visible). 


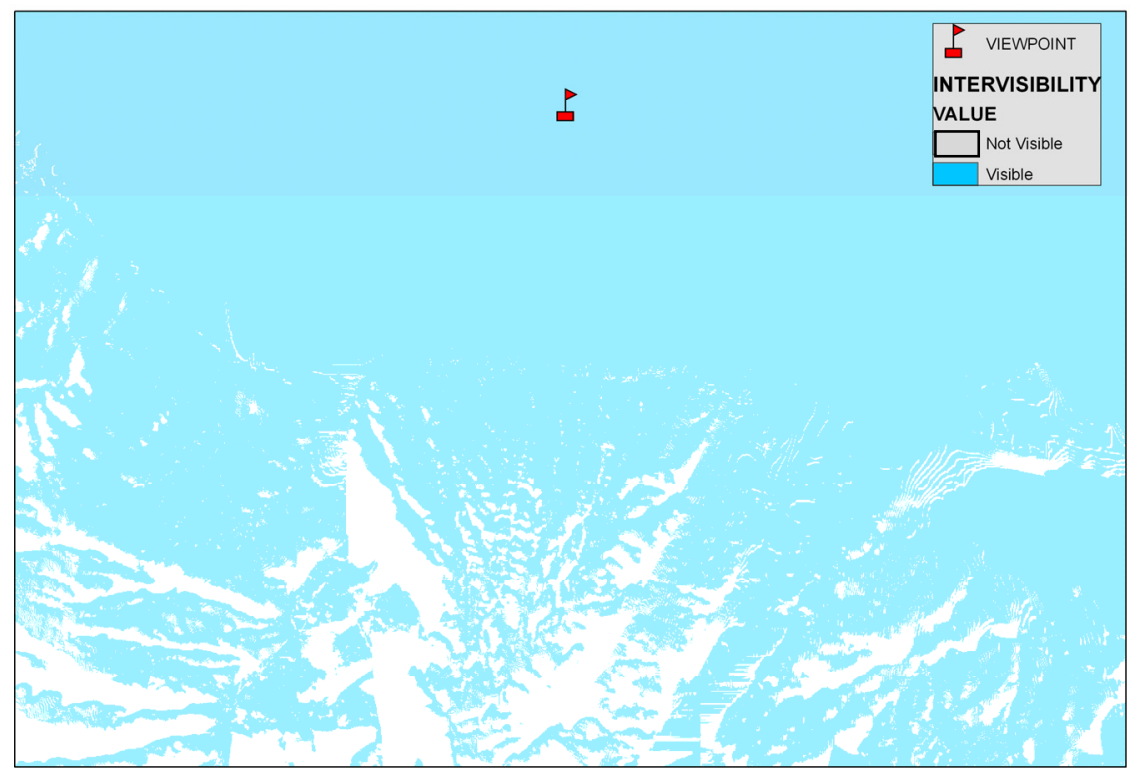

Figure 1: Example of an intervisibility map delineating visible and non-visible areas from one viewpoint.

Generally, visibility is evaluated considering more observers localized in different points of the area. Then, using a DTM, visibility from each observer it is possible to verify.

Visibility analysis is reciprocal; it can be made from both directions. In this paper viewshed tool is used to determine from which pixel can see a target located at a certain position.

The result, obtained by more observers and more targets, is a map where two colors indicate visible or not visible.

The user achieves an intervisibility map with ArcGIS, providing to the software some features such as:

- the DTM size cells;

- the height of the observation point;

- the increase to add to the surface elevation of the viewpoint (Offset A);

- the increase to add to the target surface cells (Offset B);

- the beginning and end of the angle of horizontal view (Azimuth1 and Azimuth2).

Values are in degrees from 0 to 360 , with 0 oriented to the North;

- the upper and lower vertical angle of view (Vert1 and Vert2). Values are from $-90^{\circ}$ to $+90^{\circ}$;

- the internal and external radius, Radius 1 and Radius 2 (between the rays visibility area from the point of view is delimited). 
Further, the software considers the Earth's curvature and refraction, and makes corrections on the odds provided by the DTM using the following formula:

$$
Z_{a}=Z_{s}-0,87 F\left(\frac{D^{2}}{2 R}\right)
$$

where:

$Z_{\mathrm{a}}$ is the correct value of the height (the actual height);

$Z_{\mathrm{s}}$ is the initial value of the height (the surface height);

$\mathrm{D}$ is the planimetric distance between the observer and the target;

$\mathrm{R}$ is the radius of Earth, considering equal to 6375 meters.

The simplest viewshed calculations suppose that light moves in straight lines in a Euclidean space (the Earth is not curved and no refraction occurs). This is a good approximation for distances of several kilometers. Over large distances it is necessary to consider the Earth's curvature and the transparency of the atmosphere (Burrough and McDonnell [5]), and so these parameters are taken into account for the paper, setting standard parameter provided by the software.

\section{Applications for an offshore wind farm}

The purpose of this study is to assess the visibility of an offshore wind power park still at planning. This area is localized in the Adriatic sea, along the coast of Apulia and Molise Regions, close to the town of Marina di Chieuti.

Environmental Impact Assessment project, conducted by Tecnogaia Srl behalf of the Company TREVI Energy SpA, is considered; this plan involves the installation of 50 large size turbines of the power of 3.0 MW each, for a total capacity of $150 \mathrm{MW}[7]$.

The 50 turbines will then be placed into 8 parallel rows, oriented between $50^{\circ}$ North and $60^{\circ}$ East-North East, spaced with a step of $900 \mathrm{~m}$ and the first turbine will be placed in a row distance of $5 \mathrm{~km}$ from the coast. Each row will consist of 6-7 turbines spaced with a step of about $700 \mathrm{~m}$.

The rotor ray is about $60 \mathrm{~m}$, the height of the center of the rotor from the mean sea level is $90 \mathrm{~m}$, the submerged part of the tower is between $17 \mathrm{~m}$ and $24 \mathrm{~m}$. The territorial framework of the study is presented in Figure 2.

The potential site, identified for the construction of offshore wind farm, is selected for several factors such as distance from the coast, the nature and the depth of the seabed, the possibility of connection to the national electricity grid through power lines located in coastal areas and the presence of any nontechnical constraints (military zones, marine protected areas, etc.). The visible elements of the project are, therefore, all the wind turbines.

To determine the level of visual disturbance caused by the installation it is necessary to realize a map of intervisibility that underlines the major points of visual exposure. 

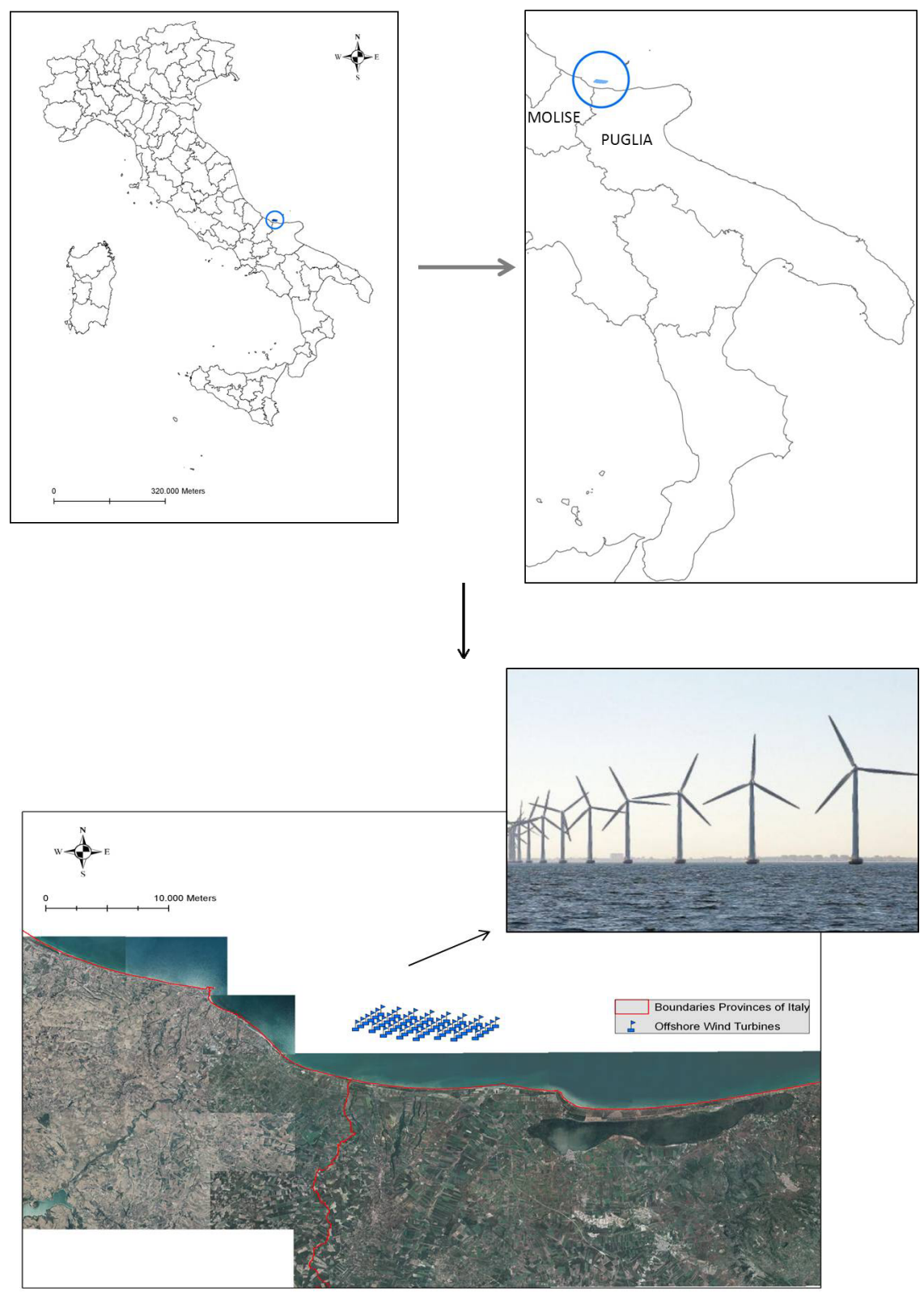

Figure 2: $\quad$ Territorial framework of the study area.

Data used in this work are the following:

1. Cartography (*.shp format) of the administrative boundaries of municipalities of the Puglia and Molise regions, referred in the UTM-WGS84 system; 
2. DTM of Puglia and Molise regions, produced by IGM (Istituto Geografico Militare) in the UTM-WGS84 system and with a grid cells size of $20 \mathrm{~m}$ x $20 \mathrm{~m}$; 3. Orthophoto (*.tif format) of the area affected by the analysis of intervisibility (flight 1998), scale 1:10.000, in the UTM-WGS84 system;

4. Points representing wind turbines in the Gauss-Boaga Roma40 System.

The aeolic generators are located in the GIS environment considering the coordinates of the turbines reported in the plan of Environmental Impact Assessment, framed in the Gauss-Boaga Roma40 System. To overlap the different layers, the UTM-WGS84 has been chosen as a reference system. So, Gauss-Boaga Roma40 data are converted in the new reference system using coordinate transformation software, Traspunto v.2.52 produced by Environmental Ministry.

Intervisibility analysis is conducted using the tool "viewshed" by software ArcGIS 9.2 (ESRI).

Because visibility analysis is reciprocal, for this study the location of each wind turbine is a point of observation, a target and it is defined from which pixel it is possible see a turbine located at a certain position (Errico et al. [8]). Intervisibility analysis allows us to study all 50 points together.

The intervisibility map produced for this study is conducted from elevation data with a $20 \mathrm{~m}$ step; the DTM used is a mosaic of Molise and Puglia, realized by PCI Geomatica v. 9.1.

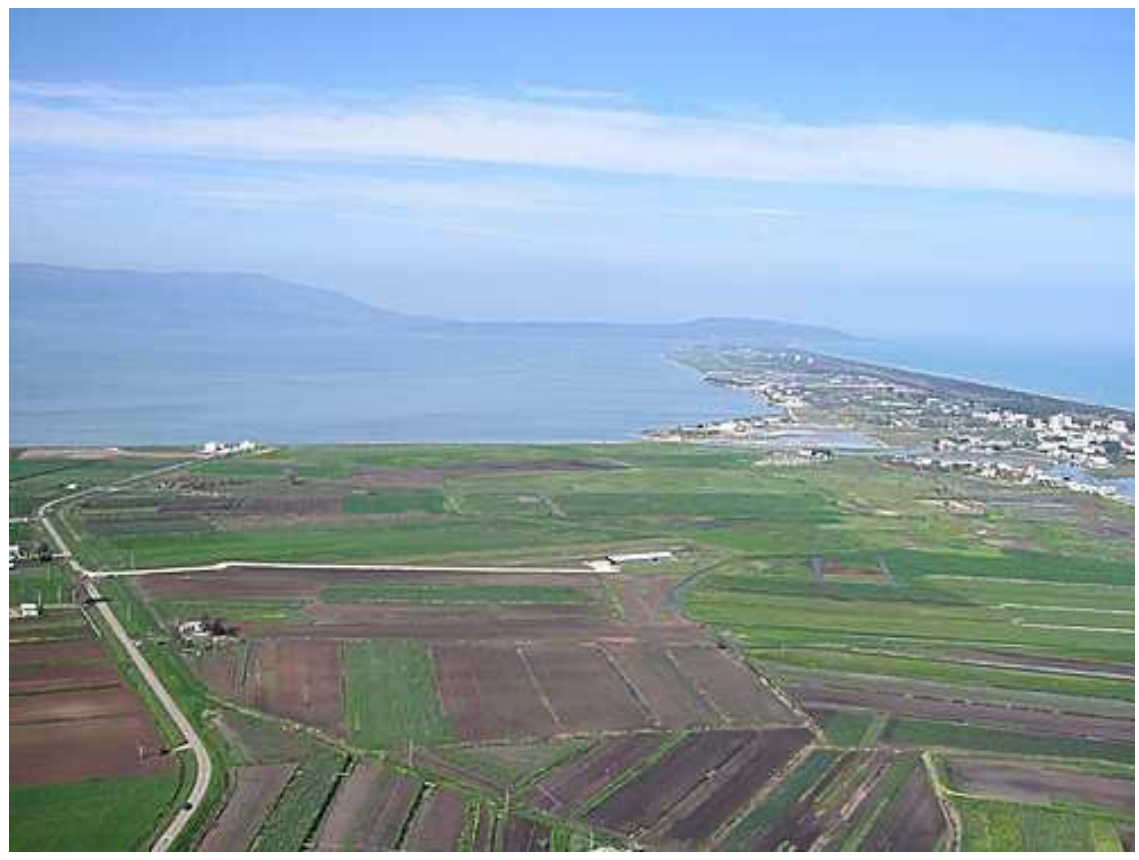

Figure 3: $\quad$ Photo of study area. 
The guidelines [2] for landscape assessment of wind farms, prepared by the Ministry of Cultural Heritage and for the assessment of visual impact, suggest that the theoretical limit of visibility should be considered equal to $20 \mathrm{~km}$. The resolving power of the human eye at a distance of $20 \mathrm{~km}$ (corresponding to a period of 1 minute or $1 / 60$ of a degree) is about $5.8 \mathrm{~m}$, which means that, at this distance, you can see objects with a size higher than about $6 \mathrm{~m}$.

For this reason a visibility ray $\mathrm{R}=20 \mathrm{Km}$ is considered in this analysis. An "offset A" equal to $150 \mathrm{~m}$ is taken into account because the effective height is represented by the ray of the rotor added to the height of the hub above sea level $(60 \mathrm{~m}+90 \mathrm{~m})$.

The Offset B is zero because is taken into account only surface elevations derived from DTM.

Azimuth1 and Azimuth2 are the parameters set by the software because for this study is necessary have a complete visibility (from $0^{\circ}$ to $360^{\circ}$ ). The same is true for Vert1 and Vert 2 (from $-90^{\circ}$ to $90^{\circ}$ ).

\section{Conclusions}

Intervisibility analysis is a useful study that may help to clarify some potential effect of new buildings in a landscape.

GIS software provides tools for quick and simple application. The studies proposed in the literature are mostly based on the identification of viewpoints and the development of an intervisibility map: in the case study in question, taking into account the bidirectionality which can be considered the phenomenon, the approach has been completely reversed.

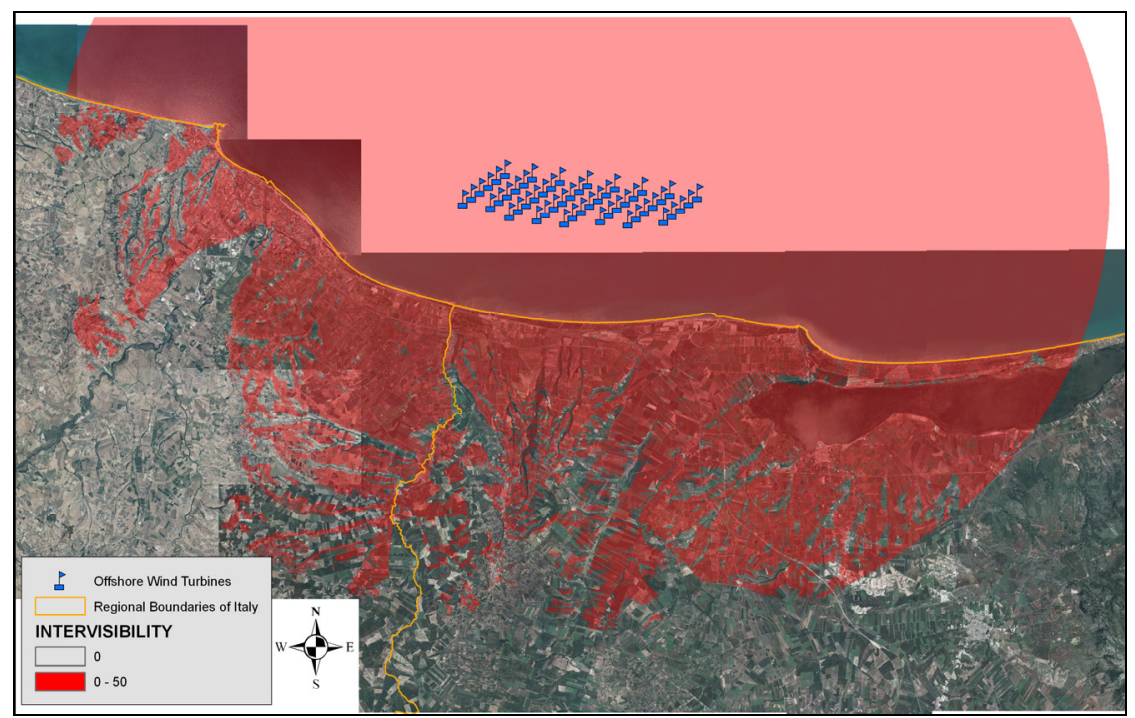

Figure 4: Viewshed analysis of study area. 
With the intervisibility map it is possible to see the potential visual effect of an aeolic farm in the landscape (figure 4) but this analysis is not an end in itself. In order to get closer to a good understanding of actual visibility, the results must be tested on the field. An appropriate ground check will establish if areas of potential visibility are areas of actual visibility or not.

\section{References}

[1] http://it.wikipedia.org/wiki/Energia_eolica

[2] Ministero dell'Ambiente, 2006. Linee Guida per l'inserimento paesaggistico degli interventi di trasformazione territoriale. Gangemi Editore, Roma, pp 34. Available at http://www.parc.beniculturali.it/ita/paesaggio/linee_guida / inserimentopaes/min_beni_imp_eolici.pdf.

[3] http://www.parc.beniculturali.it/ita/paesaggio/VIA/energiaeolica.htm

[4] Baldwin, J., Fisher, P., Wood, J. and Langford, M. Modelling Environmental Cognition of the View with GIS. 1996 (Available at http://www.ncgia.ucsb.edu/conf/SANTA_FE_CD-ROM/sf_papers/fisher_ peter/baldwin.html)

[5] Burrough A. and McDonnell R.A. Principles of Geographical Information Systems, Oxford U Press ISBN 0-19-823365-5, 2000.

[6] Sparkes A. and Kidner D. A GIS for the Environmental Impact Assessment of Wind Farms. In Proceedings of the ESRI European user conference, 1996 Available at: http://proceedings.esri.com/library/userconf/europroc $96 /$ PAPERS /PN26/PN26F.HTM

[7] Progetto Valutazione Impatto Ambientale Centrale Eolica di Chieuti: Available at:http://www.dsa.minambiente.it/via/DettaglioProgetto.aspx? ID_Progetto $=240$

[8] Errico, A., Maglione, P., Parente, C. DTM e GIS per l'analisi di intervisibilità nello studio degli impatti sul paesaggio di opere di ingegneria, Convegno Nazionale Sifet 2009, Mantova 24-26 Giugno 2009, pp. 249-258, ISBN 88-901939-7-2. 